\title{
Knowledge and Attitude about Multidrug-Resistant Tuberculosis among Healthcare Workers in Public Health Centres
}

\author{
Bony Wiem Lestari, ${ }^{1}$ Arto Yuwono Soeroto ${ }^{2}$ \\ ${ }^{1}$ Department of Public Health Faculty of Medicine Universitas Padjadjaran, ${ }^{3}$ Department of \\ Internal Medicine Faculty of Medicine Universitas Padjadjaran/Dr. Hasan Sadikin General \\ Hospital Bandung
}

\begin{abstract}
Background: Multidrug-resistant Tuberculosis (MDR-TB) is a significant public health problem and poses a threat to global tuberculosis (TB) control. In 2015, at least 504 new MDR-TB cases were identified in Indonesia. Treating MDR-TB patients is very challenging. It may take more than two years for MDR-TB treatment. Therefore, it is crucial healthcare workers (HCWs) are knowledgeable about MDR-TB. The aim of this study was to measure level of knowledge and attitude regarding MDR-TB among HCWs in public health centres.

Methods: A cross-sectional study was conducted at 73 Public Health Centres in Bandung the capital of West Java Province from August until November 2015. The samples were 73 TB nurses and 32 laboratory staff. A self-administered questionnaire was given comprising 27 knowledge questions and 29 attitude questions. Correlation between knowledge and attitude scores was calculated by Pearson correlation test.

Results: The majority of study participants were women (82.9\%), married (92.4\%), nursing staff (65.7\%) with history of TB training (98.1\%). Most of the participants were $40-59$ years old $(69.5 \%)$ with working experience in TB programme $<10$ years $(69.5 \%)$. Less than half $(38.1 \%)$ of study participants had good knowledge. In terms of attitude, more than half (53.3\%) of study participants had a positive attitude towards MDR-TB.

Conclusions: The level of knowledge among HCWs about MDR-TB is still at an unacceptable level. Certain educational interventions aim to ensure prompt diagnosis, implement infection control and accurate treatment should be established among those HCWs. [AMJ.2016;3(4):509-13]
\end{abstract}

Keywords: Attitude, health care workers, knowledge, MDR-TB, public health centre

\section{Introduction}

Tuberculosis (TB) is still a major health problem in the world. It has become one of the top ten causes of death worldwide in $2015 .^{1}$ Mycobacterium tuberculosis, as a causative agent of TB, is mostly susceptible to isoniazid (INH) and rifampin (RIF) which both are known to be the most powerful antituberculosis drugs. Strains of Mycobacterium tuberculosis which are resistant to these drugs, are termed as multidrug-resistant TB(MDR-TB). Currently, MDR-TB posed a significant thread to global TB control. ${ }^{2}$

In 2010, the World Health Organization (WHO) recommended the utilisation of Xpert MTB Rif (Xpert) as a new automated molecular diagnostic test to rapidly identify Rifampicin
Resistant-TB which can be a good proxy for MDR-TB. ${ }^{3}$ The use of Xpert is upscaled globally since it provides accurate results for RIF-resistance detection given pending results from conventional culture and drugsusceptibility testing (DST). ${ }^{4}$ As part of the Indonesian National TB Programme (NTP), efforts to upscale programmatic management of drug-resistant TB (PMDT), Xpert is used as a routine test for presumptive MDR-TB patients. ${ }^{5}$

Treating MDR-TB patients is very challenging since it has a longer course of treatment, more severe side effects, and is more toxic, more difficult to acquire and much more expensive. Furthermore, it may take more than two years for MDR-TB treatment which leads to social isolation, loss of employment, socioeconomic crisis and psychosocial burden. ${ }^{6}$

Correspondence: Bony Wiem Lestari, dr., M.Sc, Department of Public Health Faculty of Medicine, Universitas Padjadjaran, Jalan Raya Bandung-Sumedang Km.21, Jatinangor, Sumedang, Indonesia, Phone: +62 8122375633 Email: bony.wiem@gmail.com 
In 2015, at least 504 new MDR-TB cases were identified in Indonesia. Based on this alarming condition, it is crucial that healthcare providers in Indonesia are knowledgeable about MDR-TB and certain measures to control its transmission. To control MDR-TB outbreak, prompt diagnosis, infection control and effective treatment are imperative. In general, it is assumed that healthcare workers (HCWs) especially the TB nurse know about MDRTB and its consequences. However, evidence showed that HCWs do not always have enough knowledge or the proper positive attitude; and do not consistently present correct practices about prevention and treatment about MDRTB. $^{7}$

Until now, no study has been found assessing the knowledge and attitude regarding MDRTB among HCWs in Indonesia. Therefore, this study aimed to measure knowledge and attitude about MDR-TB amongst HCWs working at public health centers in Bandung Municipality.

\section{Methods}

This was a cross-sectional study in Bandung Municipality, an urban city that served as a capital city of West Java which has approximately 2.5 millions inhabitants. The city has 73 public health centers which almost half of them (30 out of 73) are equipped with a microscopy laboratory. The study population were TB nurses and laboratory staff working at public health centres within Bandung area. In this study, our sample comprised of $73 \mathrm{~TB}$ nurses and 32 laboratory staff. This study was carried out from August until November 2015.

A modified questionnaire was developed based on WHO treatment guidelines for drug-resistant $\mathrm{TB}$ and national guidelines for PMDT. $^{8}$ The questionnaire was semistructured and self-administered. Considering the small number of study population, a research assistant delivered the questionnaire and asked the study participants to fill it out. Once they had completed the questionnaires, the research assistant returned to the public health centers to collect them.

Besides questions about knowledge and attitude of MDR-TB, information about sociodemographic and professional data were also collected. The level of knowledge of MDRTB were obtained through a set of 27 questions about the definition of MDR-TB, referral criteria, transmission, symptoms, diagnosis and course of treatment. The knowledge level was classified as good if the study participants scored $>75$; fair if the score was between 5675; and poor if the score was less than 55 .

Meanwhile, to assess the level of attitude towards MDR-TB, a set of 29 questions about risk factors, transmission, infection control and role of the public health centre were asked to the study participants. The study participants were categorised as having a positive attitude when they scored above the average; and a negative if they scored below the average.

Furthermore, the research assistant checked the returned questionnaires for their completeness. Next, the data were captured in Microsoft Excel and imported into SPSS version 20 for data analysis. Then the categorical variables were presented in frequency and percentages. The correlation between knowledge and attitude scores was obtained by Pearson correlation test. The level of statistical significancy was determined when the $p$-value is $<0.05$.

This study had obtained the ethics approval from the Health Research Ethics Committee Faculty of Medicine Universitas Padjadjaran number 712/UN6.C2.1.2/KEPK/PN/2014 and the permission to conduct the survey at public health centers from the Municipal Health Office.

\section{Results}

Out of the 105 participants who received the questionnaire, 105 returned the completed questionnaire which provided a response rate of $100 \%$. The majority of study participants were female $(\mathrm{n}=87 ; 82.9 \%)$, married $(\mathrm{n}=97$; $92.4 \%)$, nursing staff $(\mathrm{n}=69 ; 65.7 \%)$ with history of TB training ( $\mathrm{n}=103 ; 98.1 \%)$. The mean age of study participants was 44.84(7.73) years old with an age range from 26 to 58 years. Based on age category, most of the participants were aged between 40-59 years $(n=73 ; 69.5 \%)$ with working experience in TB programme $<10$ years $(n=73 ; 69.5 \%)$ (Table 1).

Regarding the knowledge of MDR-TB, less than half $(38.1 \%)$ of study participants had good knowledge. Additionally, participants provided incorrect answers about definition of MDR-TB, how it is diagnosed, duration of treatment, role of public health centers in decentralised PMDT, and infection control.

In terms of attitude, more than half (53.3\%) of study participants had a positive attitude towards MDR-TB. While about 89.5\% $(n=94)$ of study participants mentioned that they were involved in providing health education about MDR-TB. Concerning the use of Xpert 
Table Sociodemographic Characteristics of Study Participants

\begin{tabular}{|c|c|c|}
\hline Variables & Frequency (n) & Percentage (\%) \\
\hline \multicolumn{3}{|l|}{ Age category } \\
\hline 20-29 years old & 3 & 2.9 \\
\hline 30-39 years old & 29 & 27.6 \\
\hline 40-49 years old & 37 & 35.2 \\
\hline 50-59 years old & 36 & 34.3 \\
\hline \multicolumn{3}{|l|}{ Gender } \\
\hline Male & 18 & 17.1 \\
\hline Female & 87 & 82.9 \\
\hline \multicolumn{3}{|l|}{ Professional category } \\
\hline TB nurse & 69 & 65.7 \\
\hline Midwife & 6 & 5.7 \\
\hline Laboratory analyst & 30 & 28.6 \\
\hline \multicolumn{3}{|c|}{ Work experience category } \\
\hline $1-5$ years & 32 & 30.5 \\
\hline $6-10$ years & 41 & 39 \\
\hline $11-15$ years & 16 & 15.2 \\
\hline $15-20$ years & 10 & 9.5 \\
\hline$>20$ years & 6 & 5.7 \\
\hline \multicolumn{3}{|l|}{ History of TB training } \\
\hline Yes & 103 & 98.1 \\
\hline No & 2 & 1.9 \\
\hline \multicolumn{3}{|l|}{ Marital status } \\
\hline Single & 4 & 3.8 \\
\hline Married & 97 & 92.4 \\
\hline Divorced & 3 & 2.9 \\
\hline Widowed & 1 & 1.0 \\
\hline \multicolumn{3}{|l|}{ Knowledge level } \\
\hline Good & 40 & 38.1 \\
\hline Fair & 55 & 52.4 \\
\hline Poor & 10 & 9.5 \\
\hline \multicolumn{3}{|l|}{ Attitude level } \\
\hline Positive & 56 & 53.3 \\
\hline Negative & 49 & 46.7 \\
\hline
\end{tabular}

in diagnosing TB among people living with HIV, about $73.4 \%(n=77)$ of study participants stated that they would refer HIV patients to be checked by Xpert whenever they had TB symptoms. With regard to negative attitudes, only $55.2 \% \quad(n=58)$ of study participants had a correct understanding about the use of $\mathrm{N}-95$ protective mask while in contact with MDR-TB patients. About 64.8\% ( $\mathrm{n}=68)$ of study participants believed that Xpert 
would be sufficient to diagnose MDR-TB. This study discovered that there was a positive association between knowledge and attitude of the participants with a correlation coefficient $(\mathrm{r})=0.44$ indicating a moderate degree of correlation between those two variables with p-value $<0.01$ which was statistically significant.

\section{Discussion}

The findings of this study showed that the majority of participants were female, middle adults and nurses. This distribution is consistent with the structure of healthcare workforce in West Java Province where 48\% are nurses and mostly women $(66.7 \%){ }^{9}$

In order to achieve the aim of this study, it was discouraging that only $38.1 \%$ of study participants had a good knowledge about MDR-TB. The inadequacy in knowledge were identified within these fields namely 1) definition of MDR-TB; 2) how it is diagnosed; 3) duration of its treatment; 4) role of public health centers in decentralised PMDT; and 5) infection control. These gaps were similar with other findings from other investigators. ${ }^{10-13}$

Based on personal characteristics of study participants such as age, gender, professional category, number of years of working experience, and history of TB training, there was no evidence from this study demonstrating that there was any significant difference among study participants with regard to their knowledge and attitude about MDR-TB.

With regard to perceived benefit of using N-95 protective mask, about 44.8\% of study participants reported that they felt uncomfortable using it when dealing with MDR-TB patients. This finding was similar with a study conducted in Georgia USA whereas only $60 \%$ of HCWs reported frequent use of respirators when in contact with TB patients. ${ }^{14}$ This perception is unacceptable since the use of N-95 mask is mandatory to prevent exposure with MDR-TB strains. Transmission of drugresistant $M$. tuberculosis can cause public drug resistance among individuals with no prior history of TB, as well as among individuals with a history of prior TB treatment. Therefore, by protecting HCWs, their family members and all other persons whom they had contact with will also be protected. ${ }^{15}$

An important finding from this study was that about $50 \%$ of study participants with good knowledge of MDR-TB were reported using the N-95 mask which was higher compared to those with insufficient level of knowledge, however, this result did not reach statistically significant. This finding suggested that any interventions which purpose to increase the level of knowledge about MDR-TB might lead to better compliance about preventive measures among HCWs.

This study revealed that $89.5 \%$ of study participants were involved in giving health education about MDR-TB to TB patients. Besides, several studies showed that there are some issues related to MDR-TB treatment which may introduce poor treatment outcomes. Some factors were associated with loss-to-follow up such as 1) lack of social support; 2) dissatisfaction with HCWs attitudes; 3 ) unstable socioeconomic status; 4) lack of counselling; and 5) poor response to therapy. ${ }^{16-19}$ Moreover, qualitative studies showed the severe side effects of MDR-TB treatment were described to be "as bad as or worse than the illness itself". ${ }^{20}$ Therefore, health education and adequate counselling related to MDR treatment especially about duration of injectable phase and total duration, also potential adverse events should be given thoroughly by HCWs to MDR-TB patients.

Another finding in this study was a significant moderate correlation $(\mathrm{r}=0.44)$ between the level of knowledge and attitude among HCWs with regard to MDR-TB. This demonstrated that educational intervention about MDR-TB combined with availability of protective equipment and monitoring practices based on clinical management guideline would support consistent behavior among HCWs towards its implementation. Moreover, systematic training and regular workshop about MDR-TB for HCWs should be conducted for improving their knowledge. A series of profesional seminars about MDR-TB for general practitioners or nurses could be a good media to distribute current update on diagnosis and treatment of this disease. Regular monitoring to health care facilities should help check HCW's compliance regarding MDR-TB management.

Furthermore, this study noticed some limitations like less variations of healthcare professionals since general practitioners, pharmacists, and counsellors had not been included. The study participants were asked about knowledge and attitude but their current practice with regard to MDR-TB were not measured comprehensively. Another limitation was that this study was a crosssectional survey; thus causal relationships could not be established.

In conclusion, the level of knowledge among 
HCWs about MDR-TB is still at an unacceptable level. Certain educational interventions aim to ensure prompt diagnosis, implement infection control and accurate treatment should be established among HCWs to make a success of PMDT

\section{References}

1. WHO. Global Tuberculosis Report. Geneva: WHO Library Cataloguing Data; 2015.

2. Furin J. The clinical management of drugresistant tuberculosis. Curr Opin PulmMed. 2007;13(3):212-7.

3. WHO. Xpert MTB/RIF implementation manual. Technical and operational 'howto': practical considerations. Geneva: WHO Library Cataloguing; 2014.

4. Steingart KR, Schiller I, Horne DJ, Pai M, Boehme CC, Dendukuri N. Xpert ${ }^{\circledR}$ MTB/ RIF assay for pulmonary tuberculosis and rifampicin resistance in adults. Cochrane Database Syst Rev. 2014;1(1):CD009593.

5. van Kampen SC, Susanto NH, Simon S, Astiti SD, Chandra R, Burhan E, et al. Effects of introducing Xpert MTB/RIF on diagnosis and treatment of drug-resistant tuberculosis patients in Indonesia: a pre-post intervention study. PLoS One. 2015;10(6): 0123536.

6. Jacobson KR, Tierney DB, Jeon CY, Mitnick CD, Murray MB. Treatment outcomes among patients with extensively drugresistant tuberculosis: systematic review and meta-analysis. Clin Infect Dis. 2010;51(1):6-14.

7. Loveday M, Thomson L, Chopra M, Ndlela Z. A health systems assessment of the KwaZulu-Natal tuberculosis programme in the context of increasing drug resistance. Int J Tuberc Lung Dis. 2008;12(9):1042-7.

8. Kemenkes RI. Pedoman Manajemen Terpadu TB Resistan Obat. Jakarta: Subdit P2PL Kementerian Kesehatan Republik Indonesia; 2014.

9. Dinas Kesehatan Provinsi Jawa Barat. Profil Kesehatan Jawa Barat. Bandung: Dinas Kesehatan Provinsi Jawa Barat; 2015.

10. Malangu N, Adebanjo OD. Knowledge and practices about multidrug-resistant tuberculosis amongst healthcare workers in Maseru. African J Prim Health Care Fam Med. 2015;7(1):774-9.

11. Mahendradhata Y, Lestari T, Probandari A, Indriarini LE, Burhan E, Mustikawati D, et al. How do private general practitioners manage tuberculosis cases? A survey in eight cities in Indonesia. BMC Res Notes. 2015;8:564.

12. Vandan N, Ali M, Prasad R, Kuroiwa C. Assessment of doctors' knowledge regarding tuberculosis management in Lucknow, India: a public-private sector comparison. Public health. 2009;123(7):484-9.

13. Kiefer EM, Shao T, Carrasquillo O, Nabeta $P$, Seas C. Knowledge and attitudes of tuberculosis management in San Juan de Lurigancho district of Lima, Peru. J Infect Dev Ctries. 2009;3(10):783-8.

14. Mirtskhulava V, Whitaker JA, Kipiani M, Harris DA, Tabagari N, Owen-Smith AA, et al. Determinants of Tuberculosis Infection Control Related Behaviors among Healthcare Workers in the Country of Georgia. Infect Control Hospital Epidemiol. 2015;36(5):522-8.

15. Zhao M, Li X, Xu P, Shen X, Gui X, Wang $L$, et al. Transmission of MDR and XDR tuberculosis in Shanghai, China. PLoS One. 2009;4(2):e4370.

16. Shringarpure KS, Isaakidis $\mathrm{P}$, Sagili KD, Baxi RK. Loss-To-Follow-Up on Multidrug Resistant Tuberculosis Treatment in Gujarat, India: The WHEN and WHO of It. PLOS ONE. 2015;10(7):e0132543.

17. Morris MD, Quezada L, Bhat P, Moser K, Smith J, Perez H, et al. Social, economic, and psychological impacts of MDR-TB treatment in Tijuana, Mexico: a patient's perspective. Int $\mathrm{J}$ Tuberc Lung Dis. 2013;17(7):954-60.

18. Johnston JC, Shahidi NC, Sadatsafavi M, Fitzgerald JM. Treatment outcomes of multidrug-resistant tuberculosis: a systematic review and meta-analysis. PloS one. 2009;4(9):e6914.

19. Orenstein EW, Basu S, Shah NS, Andrews JR, Friedland GH, Moll AP, et al. Treatment outcomes among patients with multidrugresistant tuberculosis: systematic review and meta-analysis. Lancet InfectDis. 2009;9(3):153-61.

20. Isaakidis $P$, Rangan $S$, Pradhan A, Ladomirska J, Reid T, Kielmann K. 'I cry every day': experiences of patients co infected with HIV and multidrug resistant tuberculosis. Trop Med Int Health. 2013;18(9):1128-33. 